\title{
EEN SPROOKJESACHTIGE BEESTENBOEL
}

Op 21 september 2012 bezochten leden van de VVAK in Parijs het Musée d'Ennery, dat na een jarenlange sluiting in het voorjaar weer was opengesteld. ' Dit bijzondere museum wilden wij in de eerste plaats bezichtigen als liefhebbers van Japanse en Chinese kunst. Maar omdat de oorspronkelijke U inrichting zeldzaam goed bewaard is gebleven, geeft het tevens een prachtig beeld van de passie waarmee in tweede helft van de $19^{e}$ eeuw Aziatische kunst is verzameld. Het interieur geldt bovendien als een fraai voorbeeld van Franse binnenhuiskunst.

\section{Monsters en fabeldieren}

Het grootste deel van de verzameling van Musée d'Ennery is bijeengebracht door Clémence Desgranges, geboren Lecarpentier (1823-98). Haar belangstelling voor oosterse kunst ontstond vermoedelijk rond haar twintigste jaar, toen zij van familie een verzameling Japans lakwerk en Chinees porselein erfde. Naar eigen zeggen raakte zij vooral geboeid door de afbeeldingen van Aziatische fabeldieren en de mythologische verhalen waaraan zij zijn ontleend. In de jaren daarna ging zij bij kunsthandelaren in Parijs op zoek naar nog meer oosterse monsters.

In de kennissenkring van Clémence bevonden zich de bekende Franse schrijvers Edmond (1822-96) en Jules de Goncourt (1830-70). Uit het dagboek dat deze broers jarenlang bijhielden, weten wij dat Jules de Goncourt in 1859 een bezoek bracht aan de woning van Madame Desgranges aan de Parijse Rue de l'Echiquier. Hier bewonderde hij naar schatting 150 Aziatische fabeldieren van brons, jade, porselein en bergkristal en noemde het een 'Ménagerie de la fantaisie'.

De woonvertrekken van Clémence in Parijs waren al spoedig te klein om haar groeiende verzameling te kunnen opstellen. Een deel hiervan verhuisde zij naar haar twee andere huizen, want zoals zoveel welgestelde Fransen in die tijd bezat zij een villa aan de Côte d'Azur en één aan de Normandische kust. Omdat zij haar fantastische dierenverzameling liever op één plek wilde bewaren, kocht zij in 1875 te Parijs een bouwkavel aan de Avenue du Bois de Boulogne 59, tegenwoordig Avenue Foch. Hier liet zij een groot woonhuis bouwen met voldoende ruimte voor haar kunstcollectie.

\section{Sfeervolle toonzalen}

Madame Desgranges hield van een kleurig en weelderig interieur zoals dat tijdens de regeringsperiode van keizer Napoleon III (r. 1852-70) in de mode raakte. Dat is goed herkenbaar in de zalen waar zij met veel zorg haar verzameling Aziatische kunst uitstalde. Een monumentale trap van donker hout en marmer voert naar de eerste verdieping, waar de kunstvoorwerpeen ${ }^{25: 59 \mathrm{PM}}$ 


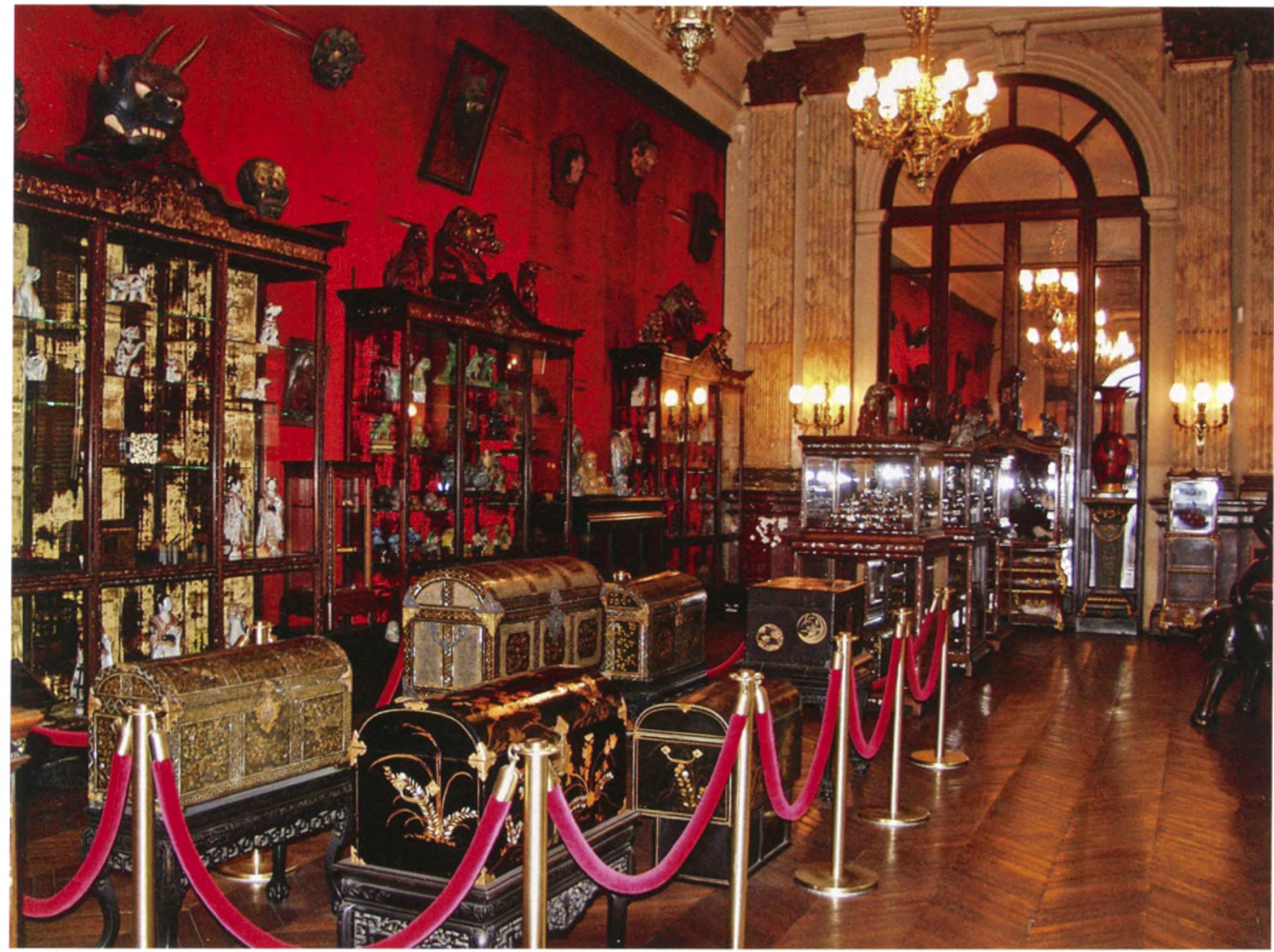

Afbeelding 1

Verzameling Nambankoffers, lakwerk, Japan, eind $16^{e}$-begin $17^{e}$ eeuw. Zaal 4 (voor de renova. tie), Musée d'Ennery. werden opgesteld in zalen met het formaat van een flinke salon. De fabeldieren en monsters stonden niet alleen in vitrines, maar werden om esthetische redenen ook los in de ruimte geplaatst. De vitrinekasten die goed moesten passen bij de getoonde voorwerpen zijn voor een groot deel vervaardigd door Gabriel Viardot (1830-1906). Deze ontwikkelde een Chinees-Japanse stijl en was in deze tijd een van de meest gewilde meubelmakers van Parijs. Van speciaal uit Azië aangevoerde houten panelen, die met parelmoer waren ingelegd, maakte hij voor het museum een groot aantal kasten. Al deze vitrines werden van binnen bekleed met zijden fluweel in prachtige kleuren.

\section{Huwelijk met Adolphe d'Ennery}

In 1881 , zes jaar na het begin van de bouw van haar nieuwe museumhuis, trouwde Clémence met de twaalf jaar oudere Adolphe-Philippe d'Ennery (1811-99). Zij was inmiddels 58 jaar oud en weduwe van haar eerste echtgenoot. D'Ennery had fortuin gemaakt als schrijver van meer dan 200 toneelstukken, opera libretto's en romans. Het huwelijk werd voltrokken in het nieuwe huis aan de Avenue du Bois de Boulogne met de beroemde schrijver Jules Verne (1828-1905) als een van de getuigen.

Samen met haar nieuwe echtgenoot breidde Clémence haar verzameling verder uit. Voor een man van zijn positie werd het bezit van een kunstverzameling in die tijd bijna beschouwd als een maatschappelijke verplich-

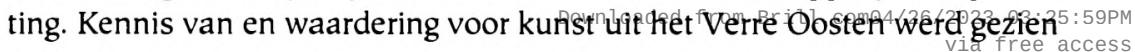






\section{Parijs, centrum van handel in Aziatische kunst}

Afbeelding 3

Zaal 5, Musée d'Ennery

Het is opmerkelijk dat de collectie van het echtpaar d'Ennery uitsluitend in Parijs is aangeschaft. Geen van beiden heeft ooit een reis naar Azië ondernomen, maar voor het aanschaffen van Aziatische kunst was dat in deze tijd ook helemaal niet nodig. In Parijs kon men kiezen uit een fenomenaal aanbod aan Japanse en Chinese kunst. Uit de door Clémence nauwkeurig bijgehouden inventarislijsten valt af te leiden dat zij kocht bij belangrijke kunsthandelaren, zoals Hayashi Tamadasa, Siegfried Bing, Philippe Sichel, maar zij kocht evengoed bij de bazaar La Porte Chinoise of het warenhuis $\mathrm{Au}$ Bon Marché.

Nadat Japan in 1854 onder druk van de Amerikaanse marine zijn grenzen had opengesteld voor de handel met buitenlanders, werd Parijs overspoeld met Japanse kunstvoorwerpen. Behalve heel veel Japanse prenten vonden ook lakdozen, kimono's, gordelknopen (netsuke), waaiers, bronzen, keramiek en rolschilderingen gretig aftrek. Deze geestdrift werd nog eens aangewakkerd door de inzending van Japan voor de Wereldtentoonstelling in 1867 in Parijs, die een ware Japanmode tot gevolg had. De Franse kunstcriticus Philippe Burty (1830-90), zelf gepassioneerd verzamelaar van Japanse kunst, gebruikte in het jaar 1872 de term japonisme voor het eerst. Hij bedoelde daarmee niet alleen de bewondering voor Japanse kunst, maar bepleitte dat studie van de kunst, geschiedenis en cultuur van Japan onmisbaar was voor Westerse kunstenaars. Toen in bijna elke woning in Europa wel iets Japans te vinden was, groeide ook het aanbod aan Chinese kunstvoorwerpen.

\section{Plannen voor een museum}

Afbeelding 4 Vitrines van $\mathrm{C}$. Viardot gewijd aan netsuke, en tijgersculptuur van gelakt hout, zaal 4 (voor renovatie), Musée d'Ennery
Omstreeks 1890 was de collectie van het echtpaar d'Ennery uitgegroeid tot ongeveer 3000 stukken. $\mathrm{Zij}$ hadden geen kinderen en zagen om zich heen hoe belangrijke kunstverzamelingen na overlijden van de eigenaar weer werden geveild. $\mathrm{Zij}$ zochten een manier om te zorgen dat hun verzameling na hun dood bij elkaar bleef. Het zal niet toevallig zijn dat overleg met Émile Guimet in 1892 de oplossing bracht. Uiteindelijk tekenden zij in 1894 de akte waarin de collectie d'Ennery werd gelegateerd aan de Franse staat.

Toen eenmaal was besloten om de collectie na te laten aan het Franse volk, zag Clémence d'Ennery aanleiding om nog eens flink uit te breiden. Zij kocht bijvoorbeeld ruim 1500 netsuke uit de Edo-periode (1603-1868) van uitzonderlijke kwaliteit. Om al deze nieuwe voorwerpen te kunnen opstellen, werden aan het woonhuis enkele grote tentoonstellingszalen bijgebouwd. Het gebeeldhouwde portret van Adolphe d'Ennery kreeg hier een prominente plaats. Na het overlijden van Madame d'Ennery in 1898 zijn er geen nieuwe aankopen meer gedaan en telde de verzameling zo'n 7000 voorwerpen. Toen in het volgende jaar haar echtgenoot overleed kwam het museum onder beheer van Musée Guimet. Op 27 mei 1908 gingen de deuren open voor het publiek.

De museumzalen bleven tot op vandaag onveranderd en de bezoeker van Musée d'Ennery krijgt het gevoel een fraai woonhuis te betreden. De oudste beschrijvingen van het museum spreken over de vele verschijningsvormen van Aziatische fabeldieren: beelden, gordelknopen, poppen, maskers en zo meer. Of zij noemen de veelheid aan materialen in de collectie: steengoed; 

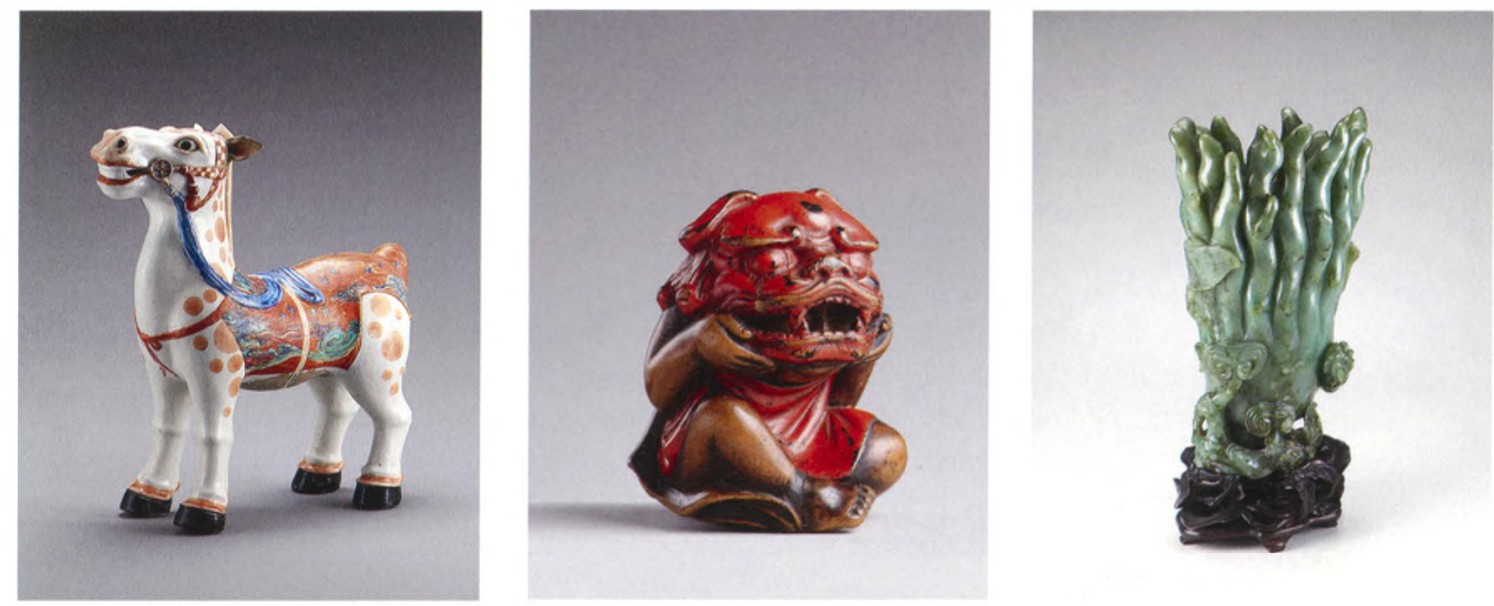

Afbeelding 5 (links) Paard, emaildecoratie, Kakiemon stijl, Japan, Edo-periode, $2^{\mathrm{e}}$ helft $17^{\mathrm{e}}$ eeuw, Musée d'Ennery.

Afbeelding 6 (midden) Netsuke, kind dat een Shishimasker optilt, rood gelakt hout, Japan, Edo-periode, Musée d'Ennery.

Afbeelding 7 (rechts) Gevingerde citroen (of Boeddha's hand), gesneden jade, China, Qing-periode, $18^{\circ}$ eeuw, Musée d'Ennery.

porselein, hout, ivoor, lakwerk, halfedelstenen. Over stijlperiodes wordt dan nog niet gesproken. Toch bevat het museum een prachtige verzameling Chinese keramiek waarin alle bekende stijlen van de Yuan- (1279-1368) tot de Qing-dynastie (1644-1911) vertegenwoordigd zijn. Daarnaast is er een bijzondere collectie jade en halfedelstenen uit de Ming- (1368-1644) en de Qing-dynastie. Ook zijn er zeldzame beelden van rood gelakt hout uit de Ming-periode en een aantal voorwerpen die speciaal waren bestemd voor gebruik door Chinese intellectuelen, de zogenaamde literati. Hiertoe rekent men grote stukken halfedelsteen (pierres dures) en bewerkte neushoorns, die geplaatst dienen te worden op een bijpassende onderzetter. Verder is er Japans steengoed en porselein uit de Edo-periode waaronder topstukken van Kakiemon- en Imari-porselein. En dan zijn er natuurlijk de bijzondere voorwerpen van Japans lakwerk uit de Momoyama- (1568-1600) en Edoperiode, waaronder een kabinet in Namban-stijl gemaakt rond 1600. Aan de wanden hangen Japanse processiemaskers van de Kamakura- (1189-1333) tot de Edo-periode en er zijn een aantal boeddhistische beelden en altaren. Wat opvalt is dat Japanse prenten geheel ontbreken.

\section{Respectvolle renovatie}

In 1996 moest het museum wegens veiligheidsredenen worden gesloten voor het publiek. Men vreesde onder meer dat de houten vloeren niet langer bestand zouden zijn tegen de druk van voorwerpen en bezoekers. Toch heeft respect voor de bedoelingen van Clémence en Adolphe d'Ennery bij de renovatie steeds voorop gestaan. Wat kapot was is zoveel mogelijk hersteld. De electriciteit is onzichtbaar aangepast aan moderne normen, het stucwerk is gerepareerd, het schilderwerk is in haar oorspronkelijke kleuren teruggebracht en de kapotte bekleding is vervangen door zoveel mogelijk gelijkende stoffen. Manufacture Prelle te Lyon, een zijdefabriek die al sinds 1752 bestaat, kon de wandbekleding voor de grootste zaal leveren in de originele rode tint en gaf het zijden fluweel voor de vitrines kado. 
Voor Hélène Bayou als modern conservator moet het zeker niet gemakkelijk zijn geweest om de voorwerpen weer precies op hun oude plek terug te plaatsen. In de vitrines moesten heel veel gelijksoortige voorwerpen bij elkaar worden gezet en ook de oude papieren bijschriften zijn erbij gelegd. Fraaie topstukken staan om esthetische redenen los in de ruimte, wat ze vanzelfsprekend kwetsbaar maakt. In de grote museumzalen die na 1892 zijn bijgebouwd kan men genieten van de decoratieve uitstalling van heel veel voorwerpen die zo kenmerkend is voor de $19^{e}$ eeuw. De maskers hangen aan de muur, de kisten van Japans lak staan op de vloer en grote objecten zijn bovenop de kasten gezet. Op subtiele wijze is wel getracht om enige uitleg te geven, zonder de exotische sfeer van het museum geweld aan te doen. In een enkele vitrine is bijvoorbeeld de indeling van een groep keramiek licht verschoven om bijzondere stukken beter uit te laten komen. Binnenkort verschijnt een uitgebreide toelichting over het museum door Hélène Bayou. Deze zal ons ongetwijfeld veel vertellen over de geschiedenis en verzameling van dit zeldzaam bewaard gebleven museum. Dankzij de uiterst precieze voorwaarden in de akte waarin het legaat is vastgelegd, is Musée d'Ennery nog grotendeels in haar oorspronkelijke staat bewaard gebleven. Gezien de radicaal veranderde opvattingen over museuminrichting mag dat wel een wonder heten.

- Musée d'Ennery is alleen toegankelijk op afspraak, met verplichte rondleiding, http://www.guimet.fr/fr/musee-dennery/informations-pratiques

Christien Smits studeerde kunstgeschiedenis aan de Vrije Universiteit te Amsterdam met als bijvak kunstgeschiedenis van Oost-Azië en als specialisatie toegepaste kunst. Zij werkte in opdracht voor musea en schreef artikelen voor museumpublicaties en tijdschriften. Daarnaast was zij enkele jaren eindredacteur van het tijdschrift Vormen uit Vuur. Samen met Christine van der Pill en bestuurslid Rosalien van der Poel vormt zij de reiscommissie van de VVAK.

\section{Literatuur}

Hélène Bayou, Le musée d'Ennery: l'alchimie d'un lieu et d'une collection. $\mathrm{http} / / \mathrm{wwww}$.guimet.fr/fr/musee-dennery/histoire-du-musee-dennery (laatst bezocht 27 januari 2013)

Persbericht Musée Guimet: Musée d'Ennery. 59, avenue Foch Paris 16 ${ }^{e}$. Réouverture du musée d'Ennery le 5 avril 2012.

Gabriel P. Weisberg, Art Nouveau Bing: Paris Style 1900, Harry N. Abrams, New York, 1986

Siegfried Wichmann, Japonisme: The Japanese Influence on Western Art in the 19th and 20th Centuries, Park Lane, New York, 1985. [Oorspr. uitg. Japonismus: Ostasien und Europa: Begegnungen in der Kunst des 19. und 20. Jahrhunderts, Schuler, Herrsching, 1980.]

\section{Noot}

1. Fotografie afbeelding 1 door Jean-Paul Pinon, Musée Guimet. Fotografie overige afbeeldingen door Raphaël Chipault en Benjamin Soligny, Musée Guimet. 


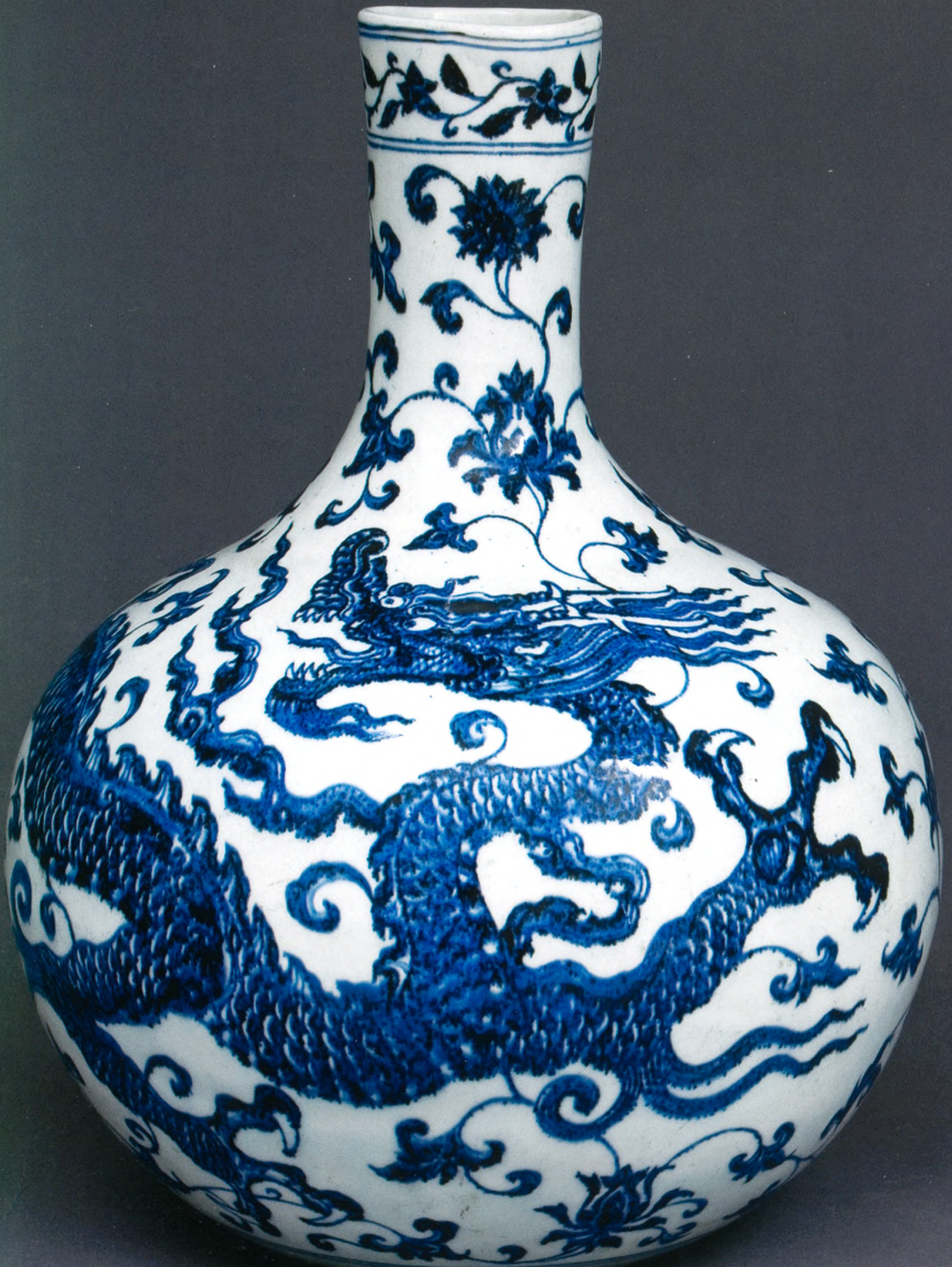

